\title{
Mycoplasma mustelae, a New Species from Mink
}

\author{
M. M. SALIH, ${ }^{1} \dagger$ N. F. FRIIS, ${ }^{2}$ S. N. ARSECULERATNE, ${ }^{1} \ddagger$ E. A. FREUNDT, ${ }^{1 *}$ AND C. \\ CHRISTIANSEN ${ }^{1}$ \\ Food and Agriculture Organization/World Health Organization Collaborating Centre for Animal \\ Mycoplasmas, Institute of Medical Microbiology, University of Aarhus, Aarhus, ${ }^{1}$ and The State Veterinary \\ Serum Laboratory, Copenhagen, ${ }^{2}$ Denmark
}

\begin{abstract}
Five rapidly growing, glucose-fermenting Mycoplasma strains were isolated from the lungs of mink kits. Biochemical and serological studies revealed that these isolates were different from all of the currently accepted Mycoplasma species and serogroups. These strains appear to constitute a new species, for which we propose the name Mycoplasma mustelae. The type strain of $M$. mustelae is strain MX9, and this strain has been deposited in the Food and Agriculture Organization/World Health Organization Collaborating Centre for Animal Mycoplasmas, Institute of Medical Microbiology, University of Aarhus, Aarhus, Denmark, as strain AMRC-C 1486, in the American Type Culture Collection, Rockville, Md., as strain ATCC 35214, and in the National Collection of Type Cultures, London, England, as strain NCTC 10193.
\end{abstract}

During an investigation of the occurrence of mycoplasmas in minks, eight strains were isolated from apparently normal lungs of 1- to 2month-old kits. Although three strains were identified as Ureaplasma (12), the remaining five isolates appeared to be rapidly growing, acid-producing mycoplasmas with classical colony morphology. A preliminary serological screening showed that these five strains were closely related and distinct from other species having similar characteristics. We undertook the present study to determine whether this group of strains constitutes a new species according to the minimal standards recommended by the Subcommittee on the Taxonomy of Mollicutes (15).

\section{MATERIALS AND METHODS}

Mycoplasma strains. The minks from which the five mycoplasma strains were isolated originated from three farms in Denmark. Three strains (one from each farm) were shown to be serologically identical by the growth inhibition test, and these three strains (strains MX8, MX9 ${ }^{\mathrm{T}}$ [type strain], and MX11) were selected for further study. Strain MX9 was chosen as representative of the group. Each strain was passed through a membrane filter (pore size, $450 \mathrm{~nm}$ ) and cloned on solid medium. This procedure was repeated three times. With three exceptions, all type and reference strains of other members of the genus Mycoplasma used in this study for serological and biological comparisons with the new organism were strains kept at the Food and Agriculture Organization/World Health

$\dagger$ Present address: Veterinary Research Administration, El Amarat, Khartoum, Sudan.

$\ddagger$ Present address: Department of Microbiology, Faculty of Medicine, University of Peradeniya, Peradeniya, Sri Lanka.
Organization Collaborating Centre for Animal Mycoplasmas. The exceptions were $M$. cricetuli, $M$. sualvi Mayfield and $M$. fastidiosum 4822, which were kindly supplied by A. Hill, MRC Experimental Embryology and Teratology Unit, Medical Research Council Laboratory, Carshalton, Surrey, England, R. N. Gourlay, Animal Research Center, Institute for Research on Animal Diseases, Compton, England, and R. H. Leach, Mycoplasma Reference Laboratory, Norwich, England, respectively. The following Mycoplasma strains and antisera were used in serological tests: $M$. agalactiae PG2, $M$. alkalescens PG51(D12), $M$. alvi Ilsley, $M$. anatis $1340, M$. arginini $\mathrm{G} 230, M$. arthritidis PG6, $M$. bovigenitalium PG11, M. bovirhinis PG43, $M$. bovis Donetta, $M$. bovoculi M165/69, M. buccale CH20247, $M$. californicum ST-6, $M$. canadense 275C, $M$. canis PG14, $M$. capricolum California kid, $M$. caviae $\mathrm{G} 122, M$. citelli RG-2C, $M$. columbinasale 694 , $M$. columbinum MMP-1, $M$. columborale MMP-4, $M$. conjunctivae HRC581, $M$. cricetuli $\mathrm{CH}, M$. cynos H831, $M$. dispar 462/2, $M$. edwardii PG24, M. equigenitalium T37, $M$. equirhinis M432/72, M. fastidiosum $4822, M$. faucium DC-333, $M$. feliminutum BEN, $M$. felis C0, M. fermentans PG18, M. flocculare Ms42, $M$. gallinaceum DD, $M$. gallinarum PG16, $M$. gallisepticum PG31, M. gallopavonis WR1, M. gateae CS, $M$. hominis $\mathrm{PG} 21, M$. hyopneumoniae J, M. hyorhinis BTS-7, $M$. hyosynoviae S16, $M$. iners PG30, $M$. iowae 695, M. lipophilum MaBy, M. maculosum PG15, $M$. meleagridis 17529, $M$. moatsii MK405, M. molare H542, $M$. mycoides subsp. capri PG3, M. mycoides subsp. mycoides PG1, $M$. neurolyticum type A, $M$. opalescens $\mathrm{MH5408,} \mathrm{M.} \mathrm{orale} \mathrm{CH19299,} \mathrm{M.} \mathrm{ovipneu-}$ moniae Y-98, $M$. pneumoniae $\mathrm{FH}, M$. primatum HRC292, M. pullorum CKK, $M$. pulmonis PG34(Ash), $M$. putrefaciens KS-1, $M$. salivarium $\mathrm{PG} 20, M$. spumans PG13, $M$. sualvi Mayfield, $M$. subdolum TB, $M$. synoviae WVU1853, $M$. verecundum 107 , avian serogroup $J$ strain DJA, avian serogroup $K$ strain DKCPA, avian serogroup $\mathrm{N}$ strain FMN, avian serogroup 
Q strain $\mathrm{L} 3-10 \mathrm{~B}$, avian serogroup $\mathrm{R}$ strain DRA-O, bovine serogroup 7 strain PG50, bovine serogroup $L$ strain B144P, ovine serogroup 5 strain goat 145, ovine serogroup 6 strain goat 189 , ovine serogroup 7 strain A1343, ovine serogroup 8 strain Y-goat, and ovine serogroup 11 strain 2D.

Medium. The organisms were cultivated in modified Hayflick medium B, as described previously $(7,8)$.

Cultural and morphological studies. Colonies were examined with a stereomicroscope at a magnification of $\times 40$ after 4 days of incubation at $37^{\circ} \mathrm{C}$ in $8 \% \mathrm{CO}_{2}$ in air in a humidified $\mathrm{CO}_{2}$ incubator. A 2-day-old culture of strain $\mathrm{MX}^{\mathrm{T}}$ was inoculated onto the standard solid medium, and the resulting plate cultures were incubated at different temperatures and under different atmospheric conditions (viz., at 22,27 , and $37^{\circ} \mathrm{C}$ in air containing about $8 \% \mathrm{CO}_{2}$ and at $37^{\circ} \mathrm{C}$ in $95 \% \mathrm{~N}_{2}-5 \%$ $\mathrm{CO}_{2}$ ). The plates were examined for growth every other day for 10 to 12 days. Colonies were stained with Giemsa stain as described by Fallon and Whittlestone (10). Broth cultures in the logarithmic phase (2 days) were studied by dark-field microscopy at a magnification of $\times 1,000$.

For examination by electron microscopy, agar blocks containing single colonies from 2-day-old cultures of strain $\mathrm{MX9} 9^{\mathrm{T}}$ were prefixed with $0.3 \%$ glutaraldehyde in Veronal-acetate buffer containing $0.01 \mathrm{M}$ $\mathrm{CaCl}_{2}$ (pH 6.1), further fixed in a $1 \% \mathrm{OsO}_{4}$ solution containing yeast extract-sodium acetate-peptone medium, and finally treated with $2 \%$ uranyl acetate. After dehydration in a graded series of acetone-water mixtures, the blocks were embedded in Vestopal-W. Sections were cut with an LKB Ultrome-III microtome and examined after poststaining with magnesium uranyl acetate and lead citrate by using a Jeol JEM 100B electron microscope (16).

Filterability. The filterability of strain $\mathrm{MX} 9^{\mathrm{T}}$ was determined by using membrane filters (Millipore Corp.) having average pore diameters of 450, 300, 220, and $100 \mathrm{~nm}$. The numbers of colony-forming units per milliliter were estimated before and after filtration.

Reversion. Strain $\mathrm{MX} 9^{\mathrm{T}}$ was transferred five times in liquid standard medium lacking bacterial inhibitors. After each of five consecutive passages, the cells were plated onto a solid medium without bacterial inhibitors and examined for bacterial colonies.

Cholesterol requirement. The cholesterol requirement on solid medium was determined by the method of Edward (4). The following three media were used: (i) medium CA, a basal medium containing $90 \mathrm{ml}$ of heart infusion agar (Difco Laboratories), $1.2 \mathrm{ml}$ of $0.2 \%(\mathrm{wt} / \mathrm{vol}$ ) deoxyribonucleic acid (DNA) solution (Sigma Chemical Co.), $0.25 \mathrm{ml}$ of benzylpenicillin $(20,000 \mathrm{IU} / \mathrm{ml})$, and $1 \mathrm{ml}$ of a $1 \%(\mathrm{wt} / \mathrm{vol})$ thallium acetate solution; (ii) medium $\mathrm{CB}$, which was the same as medium $\mathrm{CA}$, except that it also contained $0.1 \%$ (wt/vol) palmitic acid and 5\% (wt/vol) bovine serum albumin; and (iii) medium $\mathrm{CC}$, which was the same as medium $\mathrm{CB}$, except that it was supplemented with $0.05 \%(\mathrm{wt} / \mathrm{vol})$ cholesterol. The $\mathrm{pH}$ of each of these three media was 7.8. A twice-washed suspension of strain $\mathrm{MX} 9^{\mathrm{T}}$ obtained from a culture grown in $200 \mathrm{ml}$ of standard medium in which horse serum was replaced by $1 \%(\mathrm{vol} / \mathrm{vol})$ PPLO serum fraction (Difco) was diluted in 10-fold serial dilutions from $10^{\circ}$ through $10^{-6}$. A $0.01-\mathrm{ml}$ sample from each dilution was streaked onto each of the three media described above, and the inoculated plates were incubated at $37^{\circ} \mathrm{C}$ in air containing $8 \% \mathrm{CO}_{2}$. Growth was recorded every other day for 10 to 12 days.

Susceptibilities to digitonin $(1.5 \%, \mathrm{wt} / \mathrm{vol})$ and sodium polyanethol sulfonate $(5 \%, \mathrm{wt} / \mathrm{vol})$ were determined by the disk growth inhibition method (11).

Biochemical characteristics. All isolates were tested for fermentation of glucose (aerobically and anaerobically), hydrolysis of arginine and urea, phosphatase activity, serum digestion, and reduction of 2,3,5,triphenyltetrazolium chloride (aerobically and anaerobically), as described previously $(7,8)$. Formation of film and spots was determined as described by Edward (3), using the egg yolk medium (medium BY) of Fabricant and Freundt (9).

Serological tests. Antiserum to strain $\mathrm{MX} 9^{\mathrm{T}}$ was produced in rabbits as described previously (5). Hyperimmune sera prepared in rabbits against the type and reference strains listed above were generally available from the Food and Agriculture Organization/ World Health Organization Collaborating Centre for Animal Mycoplasmas. Antisera against $M$. cricetuli $\mathrm{CH}$ and $M$. sualvi Mayfield were kindly supplied by A. Hill and R. N. Gourlay, respectively; no antiserum against $M$. fastidiosum type strain 4822 was available. Strains MX8 and MX9 $9^{\mathrm{T}}$ were tested with all of the available antisera by using the indirect immunofluorescence test on agar plates (13), the agar well modification of the growth inhibition test of Black (1), and the growth precipitation test (6). Conversely, all of the type and reference strains of the Mycoplasma species and serogroups listed above were tested with strain $\mathrm{MX9}^{\mathrm{T}}$ antiserum by the same three methods. All of the type and reference strains used in the immunofluorescence, growth inhibition, and growth precipitation tests were tested with their homologous antisera as controls.

DNA base composition. DNA was extracted as previously described (2). The guanine-plus-cytosine content of the DNA was determined by the method of Schildkraut et al. (14). DNA extracted from Escherichia coli was used as a reference (buoyant density, 1.7100 $\mathrm{g} / \mathrm{cm}^{3}$ ).

\section{RESULTS}

Cultural and morphological characteristics. Colonies on solid medium had the typical "friedegg" appearance of mycoplasmas, with a marked central spot. At $37^{\circ} \mathrm{C}$ growth of strain $M X 9^{\mathrm{T}}$ appeared on plates after 1 to 2 days; the colonies were about 0.15 to $0.2 \mathrm{~mm}$ in diameter. The maximum size (about $0.7 \mathrm{~mm}$ ) was reached after 4 days. When the organism was incubated at $27^{\circ} \mathrm{C}$, colonies appeared after 5 days and attained a size of about $0.15 \mathrm{~mm}$ after 10 days. No growth was observed at $22^{\circ} \mathrm{C}$ even after 12 days. Growth was very similar whether the organism was incubated in an $8 \% \mathrm{CO}_{2}$ atmosphere or in $95 \% \mathrm{~N}_{2}-5 \% \mathrm{CO}_{2}$. The growth of strain $\mathrm{MX}^{\mathrm{T}}$ in liquid standard medium reached a maximum level after 2 days of aerobic incubation at $37^{\circ} \mathrm{C}$. Dark-field microscopy of a fluid culture of strain $\mathrm{MX} 9^{\mathrm{T}}$ in the logarithmic growth phase showed pleomorphic rings, short filamentous forms, and coccoid elements. A Giemsa- 
stained preparation of strain $\mathrm{MX} 9^{\mathrm{T}}$ contained similar structures, including filamentous branching forms. Thin-section electron micrographs revealed pleomorphic cells that were bounded by typical plasma membranes and were devoid of cell walls.

Filterability. A culture of strain $\mathrm{MX} 9^{\mathrm{T}}$ containing $10^{10}$ colony-forming units per $\mathrm{ml}$ before filtration was used. After filtration through membrane filters having pore diameters of 450 , 300,220 , and $100 \mathrm{~nm}$, the counts were $10^{10}, 10^{3}$, 0 , and 0 colony-forming units per $\mathrm{ml}$, respectively. The morphology of strain $\mathrm{MX} 9^{\mathrm{T}}$ was not altered by filtration.

Absence of reversion. No bacterium-like colonies developed on medium without inhibitors during five passages of strain $\mathrm{MX} 9^{\mathrm{T}}$.

Cholesterol requirement. The washed suspension of strain $\mathrm{MX} 9^{\mathrm{T}}$ used in the cholesterol requirement experiments contained $3 \times 10^{8}$ colony-forming units per $\mathrm{ml}$; this suspension was found to be susceptible to digitonin and polyanethol sulfonate (zones of inhibition, 8 and $5 \mathrm{~mm}$, respectively). Growth did not occur on the basal sterol-free agar medium (medium CA), whereas growth was observed on the basal medium supplemented with palmitic acid and bovine serum albumin (medium CB) inoculated with an undiluted suspension. A single colony was picked from the plate containing medium $\mathrm{CB}$ and crushed in a tube containing $1 \mathrm{ml}$ of phosphatebuffered saline ( $\mathrm{pH} 7.4)$ to remove any trace of growth medium components from the original inoculum, and new plates containing media CA, $\mathrm{CB}$, and $\mathrm{CC}$ were inoculated with this colony suspension and with 10-fold dilutions. No growth was observed on plates containing medium $\mathrm{CB}$ during 15 days of incubation, whereas on the substrate containing cholesterol (plates containing medium $\mathrm{CC}$ ) growth occurred on the plates inoculated with the undiluted suspension and with the $10^{-1}$ dilution.

Biochemical characteristics. The biochemical reactions of strains $M X 8, M X 9^{\mathrm{T}}$, and $\mathrm{MX11}$ were as follows. All three strains fermented glucose aerobically and anaerobically, but they did not hydrolyze arginine or urea. The phosphatase test was positive; 2,3,5-triphenyltetrazolium chloride was not reduced aerobically or anaerobically. Digestion of serum was not observed. A film and spot reaction was produced.

Serological characteristics. The serological examination of strains $\mathrm{MX8}$ and $\mathrm{MX} \mathrm{9}^{\mathrm{T}}$ by growth inhibition, immunofluorescence, and growth precipitation tests using antisera against the $M y$ coplasma type and reference strains listed above (except $M$. fastidiosum $4822^{\mathrm{T}}$ ) did not show any reactivity of the test organisms with any of the antisera. In tests performed with strain $M X 9^{\mathrm{T}}$ antiserum, we observed no reactions in the immunofluorescence and growth precipitation tests with any of the strains listed above; in addition no heterologous reaction was observed in the growth inhibition tests, except for a slight inhibition $(2 \mathrm{~mm})$ of $M$. mycoides subsp. mycoides PG1. The homologous immunofluorescence titers of the strain MX8 and $M X 9^{\mathrm{T}}$ antisera were $1: 160$ and $1: 320$, and their homologous zones of growth inhibition were 5 and $6 \mathrm{~mm}$ wide, respectively.

Properties of DNA. The buoyant density of the DNA was $1.6877 \mathrm{~g} / \mathrm{cm}^{3}$ (standard deviation, $0.0004 ; n=3$ ); this gave a calculated value for the guanine-plus-cytosine content of $28.2 \pm 0.3$ mol\%.

\section{DISCUSSION}

The three isolates from minks showed the same biochemical and serological characteristics, indicating that they belong to the same species. Their lack of a cell wall, their cellular morphology, their filterability through a membrane filter with a pore diameter of $300 \mathrm{~nm}$, their typical colonial morphology, and their failure to revert to a bacterial form indicate that these organisms belong to the class Mollicutes and the order Mycoplasmatales. Their susceptibilities to digitonin and sodium polyanethol sulfonate, their requirement for cholesterol for growth, their lack of spiral morphology, and their inability to hydrolyze urea place these mink strains in the family Mycoplasmataceae and the genus Mycoplasma. Strain MX9 $9^{\mathrm{T}}$ is serologically different from all other currently accepted $\mathrm{Myco}$ plasma species and serogroups, as demonstrated by immunofluorescence, growth inhibition, and growth precipitation tests. The slight oneway cross-reaction with $M$. mycoides subsp. mycoides in the growth inhibition test may be considered nonspecific, as it was not observed in the immunofluorescence and growth precipitation tests. From the morphological, biological, and serological results, we concluded that the three isolates from minks represent a new species of the genus Mycoplasma. We propose the name Mycoplasma mustelae sp. nov. (L. n. Mustela weasel, generic name of the mink Mustela vison; L. gen. n. mustelae of Mustela) for this species.

The type strain of $M$. mustelae is strain MX9. It has been deposited in the Food and Agriculture Organization/World Health Organization Collaborating Centre for Animal Mycoplasmas, Institute of Medical Microbiology, University of Aarhus, Aarhus, Denmark, as strain AMRC-C 1486, in the American Type Culture Collection, Rockville, Md., as strain ATCC 35214, and in the National Collection of Type Cultures, London, England, as strain NCTC 10193. 


\section{ACKNOWLEDGMENTS}

We thank H. Ern $\varnothing$ for production of antisera and Kirsten Peterslund, Karin Sørensen, Elisabeth Hansen, and Birthe Søby for technical assistance. We also thank R. N. Gourlay for supplying a culture of $M$. sualvi strain Mayfield and the corresponding antiserum, $\mathbf{R}$. H. Leach for providing a culture of $M$. fastidiosum strain $4822^{\mathrm{T}}$, and $\mathrm{A}$. Hill for submitting a culture of $M$. cricetuli strain $\mathrm{CH}^{\mathrm{T}}$ and antiserum against strain $\mathrm{HO}$ of the same species.

S.N.A. gratefully acknowledges a DANIDA grant for this work.

\section{ADDENDUM IN PROOF}

After this paper was accepted for publication, two additional isolates (S2A and L2A), recovered from the trachea of a mink presenting distemper-like symptoms, were identified as $M$. mustelae. Both isolates showed double cross-reactions, by GI and IMF, with each other and with strain $M X 9^{\mathrm{T}}$, and their biochemical characteristics were also identical with those of strain MX9 ${ }^{\mathrm{T}}$. Strains S2A and L2A were submitted for identification by $T$. Yagihashi, Nippon Institute for Biological Science, Tokyo, Japan. M. cricetuli was isolated by A. C. Hill from the conjunctivas of Chinese hamsters, a closely related host, and described (Int. J. Syst. Bacteriol. 33:113-117, 1983) after acceptance of this paper.

\section{LITERATURE CITED}

1. Black, F. T. 1973. Modification of the growth inhibition test and its application to human T-mycoplasmas. Appl. Microbiol. 25:528-533.

2. Christiansen, C., F. T. Black, and E. A. Freundt. 1981. Hybridization experiments with deoxyribonucleic acid from Ureaplasma urealyticum serovars I to VIII. Int. J. Syst. Bacteriol. 31:259-262.

3. Edward, D. G. ff. 1950. An investigation of the biological properties of organisms of the pleuropneumonia group, with suggestions regarding the identification of strains. $J$. Gen. Microbiol. 4:311-329.

4. Edward, D. G. ff. 1971. Determination of sterol requirement for Mycoplasmatales. J. Gen. Microbiol. 69:205210.
5. Ernø, H., K. Jurmanová, and R. H. Leach. 1973. Bovine mycoplasmas: a serological study by the metabolic inhibition test. Acta Vet. Scand. 14:511-523.

6. Ernø, H., and M. M. Salih. 1980 . The growth precipitation test as a diagnostic method for differentiation of $\mathrm{Myco}$ plasma and Acholeplasma species. Acta Vet. Scand. 21:469-481.

7. Ernø, H., and L. Stipkovits. 1973. Bovine mycoplasmas: cultural and biochemical studies. I. Acta Vet. Scand. 14:436-449.

8. Ernø, H., and L. Stipkovits. 1973. Bovine mycoplasmas: cultural and biochemical studies. II. Acta Vet. Scand. $14: 450-463$.

9. Fabricant, J., and E. A. Freundt. 1967. Importance of extension and standardization of laboratory tests for the identification and classification of mycoplasmas. Ann. N.Y. Acad. Sci. 143:50-58.

10. Fallon, R. J., and P. Whittlestone. 1969. Isolation, cultivation and maintenance of mycoplasmas, p. 211-267. In J. R. Norris and D. W. Ribbons (ed.), Methods in microbiology, vol. 3B. Academic Press, Inc., London.

11. Freundt, E. A., B. E. Andrews, H. Ernø, M. Kunze, and F. T. Black. 1973. The sensitivity of Mycoplasmatales to sodium-polyanethol-sulfonate and digitonin. Zentralbl. Bakteriol. Parasitenkd. Infektionskr. Hyg. Abt. 1 Orig. Reihe A 225:104-112.

12. Friis, N. F., K. B. Pedersen, and B. Bloch. 1980 . Ureaplasma isolated from the respiratory tract of mink. Acta Vet. Scand. 21:134-136.

13. Rosendal, S., and F. T. Black. 1972. Direct and indirect immunofluorescence of unfixed and fixed mycoplasma colonies. Acta Pathol. Microbiol. Scand. Sect. B 80:615622.

14. Schildkraut, C. L., J. Marmur, and P. Doty. 1962. Determination of the base composition of deoxyribonucleic acid from its buoyant density in $\mathrm{CsCl}$. J. Mol. Biol. 4:430443.

15. Subcommittee on the Taxonomy of Mollicutes. 1979. Proposal of minimal standards for descriptions of new species of the class Mollicutes. Int. J. Syst. Bacteriol. 29:172-180.

16. Vinther, O. 1976. Localization of urease activity in Ureaplasma urealyticum cells. Acta Pathol. Microbiol. Scand. Sect. B 84:217-224. 